\title{
Bronchial necrosis and granuloma induced by the aspiration of a tablet of ferrous sulphate
}

\author{
R. Lamaze*, P. Tréchot**, Y. Martinet ${ }^{+}$
}

Bronchial necrosis and granuloma induced by the aspiration of a tablet of ferrous sulphate. R. Lamaze, P. Tréchot, Y. Martinet. CERS Journals Ltd 1994.

ABSTRACT: Aspiration of foreign bodies occurs mainly in children and elderly people. When the foreign body is a tablet, this event can be more severe due to the local release of active molecules.

We observed spontaneously regressing bronchial necrosis and granuloma due to the aspiration of a tablet of ferrous sulphate. We stress the need to consider the possibility of aspiration of a tablet in elderly patients with acute respiratory symptoms, and the importance of an early removal of the tablet.

Eur Respir J., 1994, 7, 1710-1711.
*Service de Medécine A, Hôpital de Neufchâteau, Neufchâteau, France. **Département de Pharmacologie Clinique, Vandoeuvreles-Nancy, France. ${ }^{+}$Clinique Pneumologique Médico-Chirurgicale and INSERM U14, Vandoeuvre-les-Nancy, France.

Correspondence: Y. Martinet, Service de Pneumologie, Hôpital de Brabois, Rue du Morvan, 54511- Vandoeuvre-les-Nancy France

Keywords: Aspiration, bronchial necrosis, ferrous sulphate

Received: December 2 1993; Accepted after revision April 121994

This work was supported, in part, by a grant from Ligue Française contre le Cancer (Comité des Vosges).
Foreign body aspiration occurs mainly in young children and in elderly people [1]. When the foreign body is chemically active, it can lead, in addition to obstruction and local irritation, to granuloma and/or tissue necrosis, resulting, in some cases, in bronchial perforation and/or stenosis with haemoptysis.

We observed bronchial necrosis and granulomatous inflammation due to the aspiration of a tablet of ferrous sulphate. The spontaneous evolution was favourable.

\section{Case report}

An 83 year old woman was admitted to the emergency room for recent thoracic pains. She had been treated for years for Parkinson's disease, with levodopa $100 \mathrm{mg}$ and benserazide $25 \mathrm{mg}$ b.i.d. She had stable untreated chronic pyelonephritis, and a mild hypertension treated with nicardipine, $50 \mathrm{mg}$ b.i.d., and celiprolol, $100 \mathrm{mg}$ q.d. Because of an iron-deficiency anaemia, she was treated with Tardyferon ${ }^{\circledR}$ ( 1 tablet $q . d$.; a brownish pinkcoated tablet, containing ferrous sulphate $256.26 \mathrm{mg}$, mucoprotease $80 \mathrm{mg}$, and ascorbic acid $30 \mathrm{mg}$; Laboratoires Robapharm, Les Ulis, France).

On admission to our department, the patient complained of mild, atypical, non-squeezing thoracic pain, with a recent nonproductive cough. No definitive history of aspiration was recorded.

The patient was apyretic, and a clear expectoration progressively developed, with normal chest examination and a chest X-ray showing blunting of the right costo- diaphragmatic sinus and calcifications in the right lower lung fields. These observations were identical to those made on chest X-rays performed 2 yrs previously (fig. 1). Due to the persistance of cough, a fibreoptic bronchoscopy

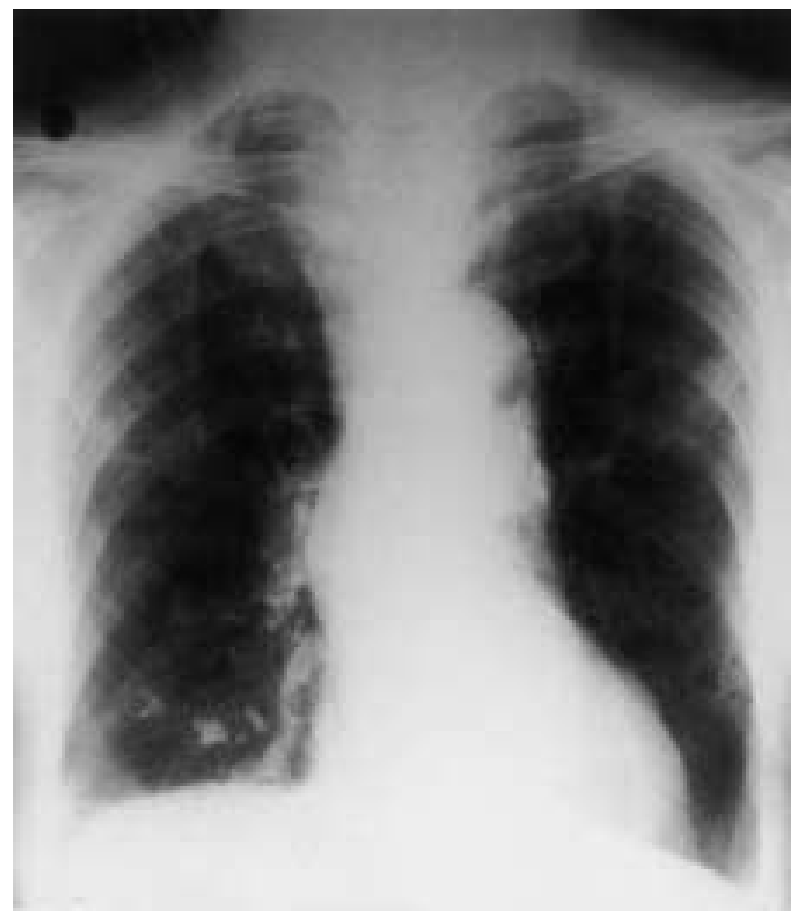

Fig. 1. - Chest X-ray, at time of admission, showing blunting of the right costodiaphragmatic sinus and calcifications in the right lower lung fields. 


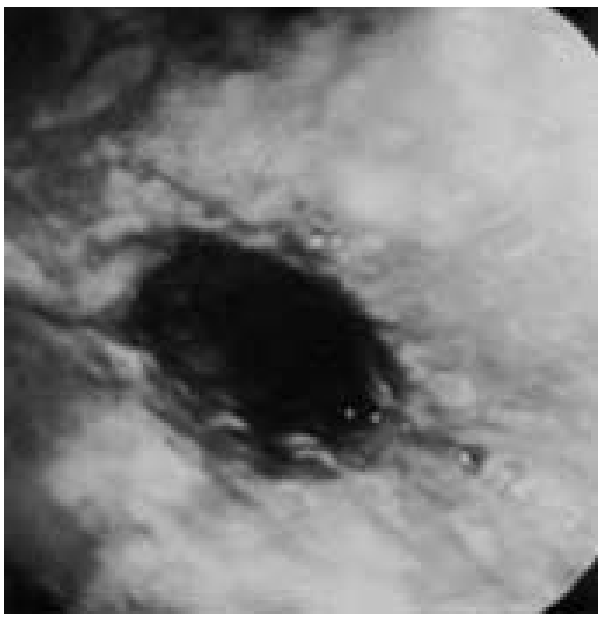

Fig. 2. - Fibreoptic bronchoscopy, 3 days after admission showing an inflammatory and necrotizing stenosis of the distal part of the intermediate bronchus.

was performed 3 days after admission, showing an inflammatory and necrotizing stenosis $(\sim 60 \%)$ of the distal part of the intermediate bronchus and of the right lower lobe bronchus (fig. 2). Otherwise, the aspect of the bronchial tree was normal. A biopsy revealed (fig. 3) a necrosis of the bronchial epithelium and of the underlying chorion, with brownish features suggesting the presence of ferrous pigment. Numerous granulomas, with epithelioid cells and a few giant cells surrounding brownish foreign bodies, were observed in small aggregates. An iron staining (Perls' colouration) was strongly positive, confirming the presence of iron. The clinical history, the observations made at fibreoptic bronchoscopy, and the pathological data strongly suggested that this patient had aspirated a tablet of ferrous sulphate.

The evolution, under local treatment with inhaled steroids, was favourable within 8 weeks, with progressive suppression of cough and a marked reduction of the inflammatory stenosis of the right lower lobe bronchus.

\section{Discussion}

Eight cases of aspiration of ferrous sulphate tablets have been reported previously, always in women (12-80 yrs of age) treated for iron-deficiency anaemia [2-6]. The tablet is usually located in the intermediate bronchus. If the tablet is not removed, the local release of ferrous sulphate leads to a brown colouration of the bronchial tree, with local necrosis. After 3-4 days, the necrosis is stable and granulomas progressively develop leading, in some cases, to stenosis. When the tablet is rapidly removed, the evolution can be favourable without significant local lesions. After a few weeks, the persistence of stenosis can require specific treatment.

The importance of removal of the tablet (as early as possible) is confirmed by the observation of a 59 year old patient, who died of massive haemoptysis 10 days after aspiration, despite the removal of the tablet 6 days previously [6]. At autopsy, a massive necrosis of the interme-

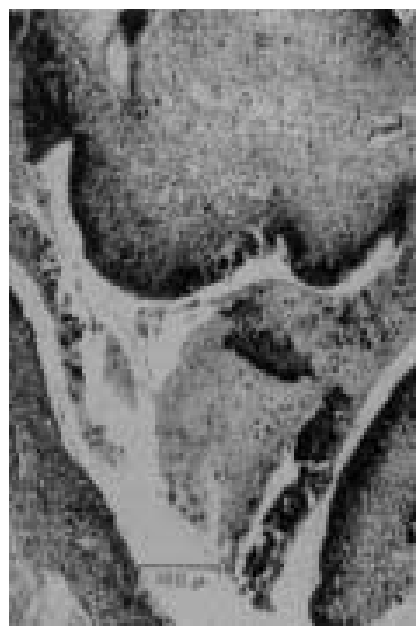

Fig. 3. - Bronchial biopsies (original magnification $\times 750, \mathrm{H} \& \mathrm{E}$ stain), showing necrosis of the bronchial epithelium and of the underlying membrane with brownish features suggesting the presence of ferrous pigment.

diate bronchus and of the walls of both the pulmonary artery and the right upper vein was observed. The local necrosis is explained by the induction of the local production of cytotoxic oxidant radicals [7].

To avoid this type of side-effect, clinicians taking care of elderly patients should teach them to sit down before swallowing tablets. Furthermore, as was the case for this patient, it is very likely that conditions such as Parkinson's disease can be the cause of foreign body aspiration due to swallowing disorders. When available, syrup may be safer. Finally, doctors in the emergency room should remember that any acute respiratory symptom in such patients can be due to tablet aspiration.

\section{References}

1. Hill SN, Main ANH, Fuggle WJ. Covert inhalation of tablet causing fatal pneumonia. Postgrad Med J 1988; 64: 66-67.

2. Melillo G, Scala G, Chiummariello A, Palumbo U. Sténose de la bronche principale gauche, secondaire à l'inhalation d'un medicament à base de sulfate ferreux. Bronches 1975; 25: 184-188.

3. Hirschler-Schlute CJW, Van Der Wal AM, Edens ET. Aspiratie van Fero-gradumet. Ned T Geneesk 1981; 125 : 15-17

4. Hackl H. Nekrotisierende Bronchitis durch versehentliche Eisensulfat-Aspiration. Atemw-Lungenkr 1989; 15: 205-207.

5. Mizuki M, Onizuka O, Aoki T, Tsuda T. A case of remarkable bronchial stenosis due to aspiration of delayed-release iron tablet. Nippon Kyobu Shikkan Gakkai Zasshi 1989; 27: 234-239

6. Evrard C, Coffin O, Kaladji C, Brun J, Benard Y, Doumert J. Hémoptysie massive 10 jours après extraction bronchique d'un comprimeé de sulfate ferreux inhalé accidentellement. Presse Med 1990; 19: 34.

7. Aust SD, Morehouse LA, Thomas GE. Role of metals in oxygen radical reactions. J Free Rad Biol Med 1985; 1: $3-25$ 